\title{
Case Report: A Case of Scrub Typhus Complicated by Adult Respiratory Distress Syndrome and Successful Management with Extracorporeal Membrane Oxygenation
}

\author{
Woo Young Choi, ${ }^{1}$ Seung Yun Lee, ${ }^{1}$ Hea Yoon Kwon, ${ }^{1}$ Jae Hyoung Im, ${ }^{1}$ Areum Durey, ${ }^{1}$ Ji Hyeon Baek,,${ }^{1}$ Young Sam Kim, ${ }^{2}$ \\ Jae-Seung Kang, ${ }^{3}$ and Jin-Soo Lee ${ }^{1 *}$ \\ ${ }^{1}$ Department of Internal Medicine, Inha University School of Medicine, Incheon, Korea; ${ }^{2}$ Department of Thoracic and Cardiovascular Surgery, \\ Inha University School of Medicine, Incheon, Korea, ${ }^{3}$ Department of Microbiology, \\ Inha University School of Medicine, Incheon, Korea
}

\begin{abstract}
A 67-year-old woman was diagnosed as having scrub typhus with pneumonitis. On admission, she was started on a combination therapy with levofloxacin and doxycycline. However, the patient developed severe acute respiratory distress syndrome (ARDS) on the 2nd day, and as a result, she underwent extracorporeal membrane oxygenation (ECMO). She was weaned from ECMO on the 10th day, as her respiratory status gradually improved. She was discharged without sequelae on the 23rd day. The outcome suggests that the use of ECMO should be considered for patients with ARDS induced from scrub typhus.
\end{abstract}

\section{INTRODUCTION}

Scrub typhus, also known as a tsutsugamushi disease, is an acute lethal infectious disease caused by Orientia tsutsugamushi. It is an endemic to a $13,000,000 \mathrm{~km}^{2}$ area of the Asia-Pacific rim, extending from Afghanistan to China, Korea, the islands of the southwestern Pacific, and northern Australia. ${ }^{1}$ A billion people are at risk, and nearly a million cases are reported each year. ${ }^{2}$

Scrub typhus is one of the differential diagnosis for fever with thrombocytopenia or hemorrhage. ${ }^{3}$ Scrub typhus can manifest with either nonspecific febrile illness or constitutional symptoms (fever, rash, myalgia, and headache), or with organ dysfunction, such as the kidney (acute kidney injury), lung (pneumonia), heart (myocarditis), liver (hepatitis), and central nervous system (meningitis). ${ }^{4-10}$ Although most patients rapidly improve with appropriate antibiotic therapy, a small percentage of cases experience serious complications. ${ }^{3}$

Acute respiratory distress syndrome (ARDS) is a serious complication of scrub typhus that occurs when fluid leaks into the alveoli as a result of sepsis. The incidence of ARDS in the general adult population was reported to be 15.3 of 100,000 in Northeast Ohio in 2002. ${ }^{11}$ The incidence of ARDS in subjects with scrub typhus is much higher than that in general adult population. ${ }^{7,12}$ Approximately $1-15 \%$ of scrub typhus patients also had ARDS. 7,13,14

Extracorporeal membrane oxygenation (ECMO) is a therapeutic tool for providing life support to patients with the inability for the lungs or hearts to maintain sufficient oxygenation in the body. ECMO involves placing patients on a vascular circuit with a membrane oxygenator that temporarily takes over the gas exchange function of the lungs. There have been an increasing number of clinical reports documenting the use of ECMO in severe ARDS patients who failed to respond to conventional mechanical ventilation therapy. ${ }^{15}$ Herein, we describe a case of scrub typhus complicated by ARDS that was successfully managed with ECMO.

*Address correspondence to Jin-Soo Lee, Division of Infectious Diseases and Infection Control Unit, Department of Internal Medicine, Inha University School of Medicine, 27 Inhang-ro, Jung-gu, Incheon, Korea. E-mail: ljinsoo@inha.ac.kr

\section{CASE}

A 67-year-old woman was admitted with fever and maculopapular rash on the whole body. She had been a healthy woman without any specific medical history. Three weeks before admission, she had been to a farm and harvested persimmons from a tree in a rural part of Chungcheongnamdo. Thereafter, 4 days before coming to our hospital, she was admitted to a nearby hospital exhibiting signs of fever and skin rash. Paracetamol was given for fever control without much improvement; and when she manifested low blood pressure, she visited our emergency department.

On admission, she was alert, but her physical examination revealed a rash on the whole body with eschar on the right armpit (Figure 1). Her body temperature was $39.6^{\circ} \mathrm{C}$, blood pressure was $100 / 60 \mathrm{mmHg}$, and pulse rate was 90 beats per minute. Her chest radiography showed bilateral pulmonary infiltration (Figure 2A). The initial arterial blood gas analysis (ABGA) revealed the following: $\mathrm{pH}, 7.44 ; \mathrm{PaCO}_{2}$, $34.2 \mathrm{mmHg} ; \mathrm{PaO}_{2}, 46.1 \mathrm{mmHg} ; \mathrm{HCO}_{3}^{-}, 22.9 \mathrm{mmol} / \mathrm{L}$; and oxygen saturation, $84.8 \%$. Her hemoglobin level was $12.6 \mathrm{~g} /$ $\mathrm{dL}$, hematocrit was $35.3 \%$, white blood cell count was 10,160 / $\mu \mathrm{L}$, and platelet count was $149,000 / \mu \mathrm{L}$. Serum blood urea nitrogen and creatinine levels were 28.3 and $0.74 \mathrm{mg} / \mathrm{dL}$, respectively. The total bilirubin level was $0.5 \mathrm{mg} / \mathrm{dL}$; aspartate aminotransferase, $59 \mathrm{IU} / \mathrm{L}$; alanine aminotransferase, $55 \mathrm{IU} / \mathrm{L}$; and alkaline phosphatase, $340 \mathrm{IU} / \mathrm{L}$. Other laboratory tests revealed glucose, $135 \mathrm{mg} / \mathrm{dL}$; C-reactive protein, $16.39 \mathrm{mg} / \mathrm{dL}$; activated partial thromboplastin time, $41.2 \mathrm{sec}-$ onds; prothrombin time, 13.7 seconds. She was admitted to the intensive care unit, with an oxygen inhaler of $5 \mathrm{~L} /$ minute via nasal prong cannular. An indirect fluorescent antibody test for O. tsutsugamushi revealed a titer of 1:1,280.

An intravenous (IV) levofloxacin (750 mg every 24 hour, from hospital day [HD] 1 to HD 13) was administered. Levofloxacin was given for a long time because of severe infection and the possibility of any other coinfection. Doxycycline (100 mg bid, from HD 1 to HD 2 and HD 6 to HD 21) was administered via a Levin tube. An IV azithromycin (500 mg every 24 hour, from HD 2 to HD 4) was administered. Physiologic doses of steroid (hydrocortisone, $200 \mathrm{mg} /$ day) were also administered as an adjuvant therapy for refractory shock.

On HD 2, even with hyperbaric oxygen therapy, oxygen saturation was not maintained (dropped by 50\%) and lead 


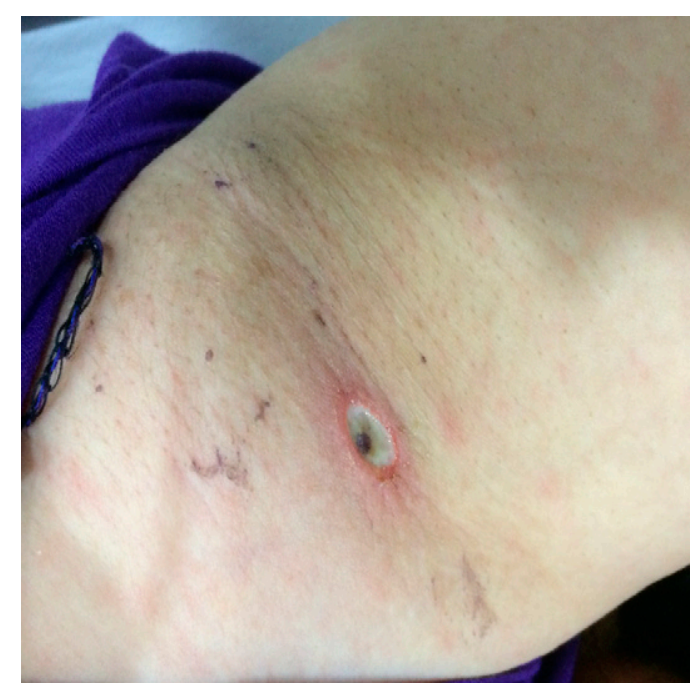

FIGURE 1. Eschar: a clinical photograph showing an erythematous papule on the right armpit. The scab might have been peeled away.

to the development of ARDS (Figure 2B); thereafter, she was mechanically ventilated. Despite high ventilator support (fraction of inspired oxygen $\left[\mathrm{FiO}_{2}\right], 1.0$ ), oxygen saturation was only $83 \%$. She was changed to a prone position after
3 hours. A follow-up ABGA revealed an exacerbated pulmonary status: $\mathrm{pH}, 7.20 ; \mathrm{PaCO}_{2}, 45.0 \mathrm{mmHg} ; \mathrm{PaO}_{2}, 53.0 \mathrm{mmHg}$; $\mathrm{HCO}_{3}{ }^{-}, 17.6 \mathrm{mmol} / \mathrm{L}$; and oxygen saturation, $78 \%$. The patient was on a continuous mandatory ventilation mode with a tidal volume of $320 \mathrm{~mL}$, respiratory rate of 24/minute, $\mathrm{FiO}_{2}$ of 1.0, and positive end-expiratory pressure of $15 \mathrm{~cm} \mathrm{H} \mathrm{H}_{2} \mathrm{O}\left(\mathrm{PaO}_{2} / \mathrm{FiO}_{2}\right.$ ratio $=53$ ). Other laboratory results were normal, and urine output was maintained. To deliver sufficient oxygen and to avoid pulmonary oxygen toxicity, veno-venous ECMO was instituted. As a drop of blood pressure was shown after ECMO, a low level of inotropics (norepinephrine, up to $10 \mu \mathrm{g} / \mathrm{minute}$ ) was used, which was then tapered out. Fortunately, there was no other organ damage. During the 9th day of ECMO, no complications related to extracorporeal circulation occurred. Throughout the 7 th days post initiation of ECMO, radiographic abnormalities and arterial oxygenation progressively improved (Figure 2C). On HD 10, ECMO was discontinued. The ventilator was also weaned off and extubation was done 3 days after the discontinuation of ECMO (on HD 13). She was discharged without sequelae after a total of 23 days in the hospital (Figure 2D).

\section{DISCUSSION}

Scrub typhus is a zoonosis caused by $O$. tsutsugamushi. The reservoirs for infection are the chigger (larva of

A

B

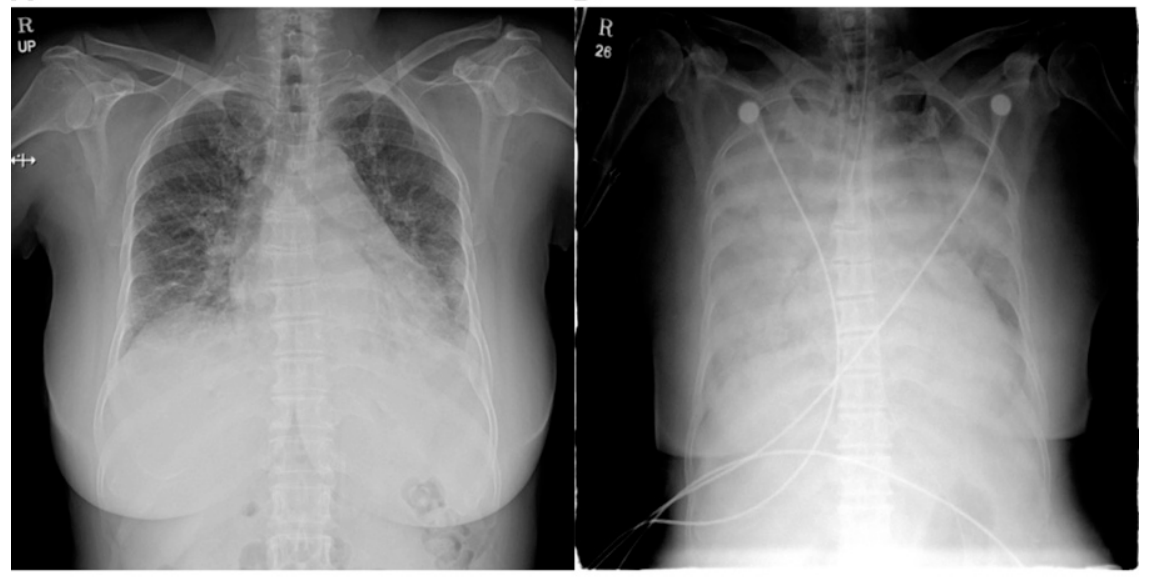

C

D

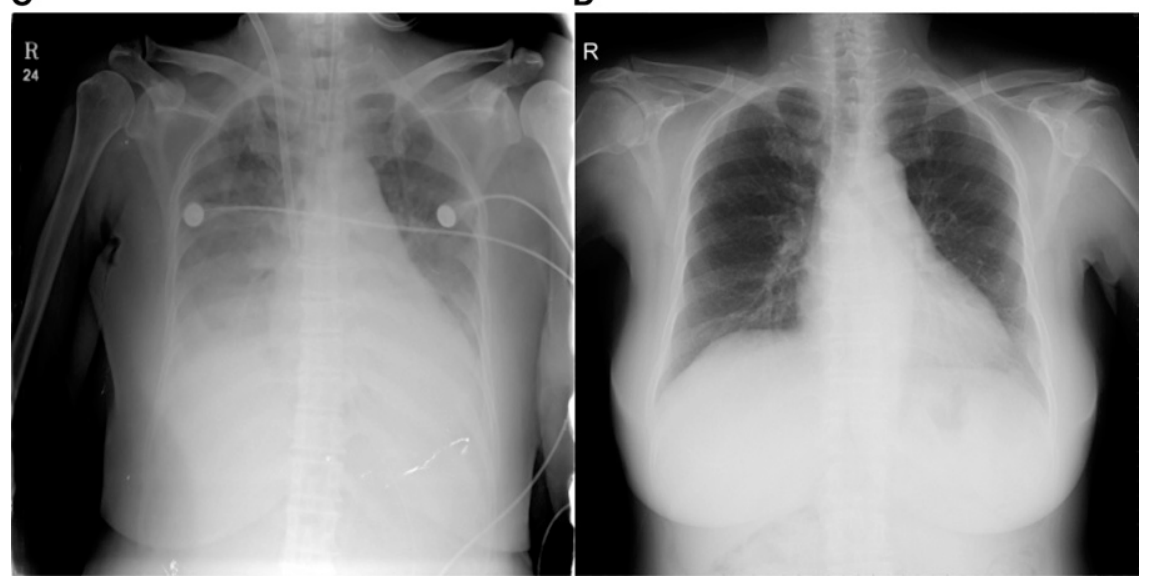

FIGURE 2. (A) On admission day: bilateral pulmonary infiltration. (B) On hospital day (HD) 2: acute respiratory distress syndrome. (C) On HD 10: improving state. (D) On HD 23: almost recovered by chest radiography. She has been discharged. 
trombiculid mite) and humans are accidentally infected. It is transmitted by trombiculid mites in long grasses and in dirtfloor homes.

Orientia tsutsugamushi is an obligate intracellular gramnegative bacterium that proliferates within the endothelial cells of small vessels in humans. Systemic vasculitis and perivasculitis are the hallmarks of scrub typhus, which cause increased vascular permeability and hypoperfusion in the tissue. ${ }^{16-19}$ Scrub typhus manifests as either nonspecific febrile illness or multi-organ dysfunction, such as acute kidney injury, ARDS, myocarditis, hepatitis, and meningoencephalitis. ${ }^{4-10}$ The involvement of lungs has been described to range from bronchitis and interstitial pneumonitis to ARDS. ${ }^{6,20,21}$

ARDS is characterized by diffuse pulmonary infiltrates in the X-ray appearance and pathologically by diffuse alveolar damage caused by an insult to the pulmonary capillary endothelium and the alveolar epithelium. ${ }^{22}$ ARDS is one of the serious complications of scrub typhus, which is associated with high morbidity and mortality. ${ }^{7}$ Although the pathogenesis of ARDS in scrub typhus is not yet well established, the increase of cytokine due to immunologic response can be suggested. ${ }^{23}$ Moreover, there has been a reported case where O. tsutsugamushi was cultured from bronchoalveolar lavage. $^{24}$ With appropriate antibiotics, like doxycycline, serious complications such as ARDS or disseminated intravascular coagulation are rarely seen. ${ }^{25,26}$ In this case, as our patient did not have any specific medical history, there were no multi-organ failures, except the lung. Despite the administration of doxycycline, 4 days after the onset of fever, ARDS has occurred. The reason is not clear. However, we can consider the following reasons. There is a possibility that a coinfection from another pathogen that we did not detect may have induced ARDS. Another reason less likely could be the infection by doxycycline-resistant strain reported in northern Thailand but there have not been cases reported in Korea. $^{27}$ The patient in this case had also shown response to doxycycline finally.

In a retrospective study, it was reported that $1.7 \%$ of scrub typhus patient had ARDS, and the mortality rate of ARDS was up to $36 \% .{ }^{14}$ As in our case, in spite of the prompt use of antibiotics, the occurrence of ARDS may be inevitable, which can even be fatal. Thus, to improve the prognosis of ARDS, appropriate treatments to sustain an appropriate level of oxygen are important; and ECMO can take such role. In this case, ECMO was a useful bridge for the conventional ventilator therapy. The quick decision to use ECMO was key to shorten the delay of oxygenation.

However, one of the factors to be considered in such a case is the pharmacokinetics of the medications administered. ECMO involves massive influx and efflux of fluids via catheters, which consequently alter the volumes of distribution, elimination of half-lives, and protein bindings of drugs. Furthermore, the inflammatory activation induced by the extracorporeal circulation and exposure of blood to foreign material and the drug sequestration in the circuit both contribute to alteration in antibiotic concentration and halflife. For these reasons, dose requirements may change if ECMO is being instituted. Since patients receiving ECMO commonly face severe infections, correct dosing is of paramount importance to improve survival. Although there are no studies regarding doxycycline and levofloxacin yet, efforts to find the appropriate dose are in progress. Therapeutic drug monitoring (whenever available) or population pharmacokinetics, based on readily available clinical and laboratory data, should help tailor antibiotic dosing to the individual patient.

In recently published large cohort of 623 patients hospitalized with scrub typhus of varying severity from mild to critically ill, the mortality rate was $9 \% .{ }^{28}$ The mortality rate for sicker patients admitted to the intensive care unit with multiorgan failure was $24 \% .{ }^{29}$ Fortunately, the mortality rate is on the decline. ${ }^{3}$ These observations should encourage clinicians to approach scrub typhus infection with optimism and to provide more aggressive care, such as ECMO.

Received January 31, 2016. Accepted for publication May 29, 2016.

Published online July 25, 2016.

Acknowledgment: This work was supported by a research grant from Inha University Hospital.

Authors' addresses: Woo Young Choi, Seung Yun Lee, Hea Yoon Kwon, Jae Hyoung Im, Areum Durey, Ji Hyeon Baek, Young Sam Kim, and Jin-Soo Lee, Department of Internal Medicine, Inha University Hospital, Incheon, Korea, E-mails: winsomew@naver .com, sylin23@naver.com, haeyoon85@daum.net, dylife83@naver .com, arkim1202@inhauh.com, jhbaek@inha.ac.kr, yskim0922@ inhauh.com, and ljinsoo@inha.ac.kr. Jae-Seung Kang, Department of Microbiology, Inha University College of Medicine, Incheon, Korea, E-mail: jaeskang@inha.ac.kr.

\section{REFERENCES}

1. Kelly DJ, Fuerst PA, Ching WM, Richards AL, 2009. Scrub typhus: the geographic distribution of phenotypic and genotypic variants of Orientia tsutsugamushi. Clin Infect Dis 48: S203-S230.

2. Watt G, Parola P, 2003. Scrub typhus and tropical rickettsioses. Curr Opin Infect Dis 16: 429-436.

3. Peter JV, Sudarsan TI, Prakash JA, Varghese GM, 2015. Severe scrub typhus infection: clinical features, diagnostic challenges and management. World J Crit Care Med 4: 244-250.

4. Devine J, 2003. A review of scrub typhus management in 20002001 and implications for soldiers. J Rural Remote Environ Health 1: 14-20.

5. Vikrant S, Dheer SK, Parashar A, Gupta D, Thakur S, Sharma A, Kaushal SS, Kanga A, 2013. Scrub typhus associated acute kidney injury - a study from a tertiary care hospital from western Himalayan State of India. Ren Fail 35: 1338-1343.

6. Wang CC, Lai YF, Wong SL, 1999. Adult respiratory distress syndrome caused by scrub typhus-a case report. Thorac Med 14: 89-93.

7. Wang CC, Liu SF, Liu JW, Chung YH, Su MC, Lin MC, 2007. Acute respiratory distress syndrome in scrub typhus. $\mathrm{Am} \mathrm{J}$ Trop Med 76: 1148-1152.

8. Sittiwangkul R, Pongprot Y, Silviliarat S, Oberdorfer P, Jittamala $\mathrm{P}$, Sirisanthana V, 2008. Acute fulminant myocarditis in scrub typhus. Ann Trop Paediatr 28: 149-154.

9. Chung JH, Lim SC, Yun NR, Shin SH, Kim CM, Kim DM, 2012. Scrub typhus hepatitis confirmed by immunohistochemical staining. World J Gastroenterol 18: 5138-5141.

10. Kar A, Dhanaraj M, Dedeepiya D, Harikrishna K, 2014. Acute encephalitis syndrome following scrub typhus infection. Indian J Crit Care Med 18: 453-455.

11. Arroliga AC, Ghamra ZW, Perez TA, Perez TP, Komara JJ, Smith A, Wiedemann HP, 2002. Incidence of ARDS in an adult population of northeast Ohio. Chest 121: 1972-1976.

12. Tsay RW, Chang FY, 2002. Acute respiratory distress syndrome in scrub typhus. Q J Med 95: 126-128.

13. Tseng CC, Tung HH, Wu SF, Wang TJ, 2012. Acute respiratory distress syndrome following scrub typhus: a case report. $J \mathrm{Am}$ Acad Nurse Pract 24: 160-165.

14. Kim SY, Jang HJ, Kim H, Shin K, Kim MH, Lee K, Kim KU, Park HK, Lee MK, 2014. Patients with acute respiratory 
distress syndrome caused by scrub typhus: clinical experiences of eight patients. Korean J Crit Care Med 29: 189-193.

15. Hemmila MR, Rowe SA, Boules TN, Miskulin J, Mc Gillicuddy JW, Schuerer DJ, Haft JW, Swaniker F, Arbabi S, Hirschl RB, Bartlett RH, 2004. Extracorporeal life support for severe acute respiratory distress syndrome in adults. Ann Surg 240: $595-605$.

16. Dogra S, 2010. Recent advances in understanding pathophysiology of scrub typhus. JK Science 12: 70-71.

17. Rapmund G, 1984. Rickettsial diseases of the Far East: new perspectives. $J$ Infect Dis 149: 330-338.

18. Koh GC, Maude RJ, Paris DH, Newton PN, Blacksell SD, 2010. Diagnosis of scrub typhus. Am J Trop Med Hyg 82: 368-370.

19. Choi YH, Kim SJ, Lee JY, Pai HJ, Lee KY, Lee YS, 2000. Scrub typhus: radiological and clinical findings. Clin Radiol 55: $140-144$.

20. Song SW, Kim KT, Ku YM, Park SH, Kim YS, Lee DG, Yoon SA, Kim YO, 2004. Clinical role of interstitial pneumonia in patients with scrub typhus: a possible marker of disease severity. J Korean Med Sci 19: 668-673.

21. Park JS, Jee YK, Lee KY, Kim KY, Myong NH, Seo PW, 2000. Acute respiratory distress syndrome associated with scrub typhus: diffuse alveolar damage without pulmonary vasculitis. J Korean Med Sci 15: 343-345.

22. Tomashefski JF Jr, 2000. Pulmonary pathology of acute respiratory distress syndrome. Clin Chest Med 21: 435-466.
23. Tseng BY, Yang HH, Liou JH, Chen LK, Hsu YH, 2008. Immunohistochemical study of scrub typhus: a report of two cases. Kaohsiung J Med Sci 24: 92-98.

24. Angelakis E, Patrick G, Peloni JM, Wey PF, Perreal C, Raoult D, 2015. Orientia tsutsugamushi in lung of patient with acute respiratory distress syndrome, France, 2013. Emerg Infect Dis 21: $373-375$

25. Berman SJ, Kundin WD, 1973. Scrub typhus in Vietnam: a study of 87 cases. Ann Intern Med 79: 26-30.

26. Brown GW, Saunders JP, Singh S, Huxsoll DL, Shirai A, 1978. Single dose doxycycline therapy for scrub typhus. Trans $R$ Soc Trop Med Hyg 72: 412-416.

27. Watt G, Chouriyagune C, Ruangweerayud R, Watcharapichat P, Phulsuksombati D, Jongsakul K, Teja-Isavadharm P, Bhodhidatta D, Corcoran KD, Dasch GA, Strickman D, 1996. Scrub typhus infections poorly responsive to antibiotics in northern Thailand. Lancet 348: 86-89.

28. Varghese GM, Trowbridge P, Janardhanan J, Thomas K, Peter JV, Mathews P, Abraham OC, Kavitha ML, 2014. Clinical profile and improving mortality trend of scrub typhus in south India. Int J Infect Dis 23: 39-43.

29. Griffith M, Peter JV, Karthik G, Ramakrishna K, Prakash JA, Kalki RC, Varghese GM, Chrispal A, Pichamuthu K, Iyyadurai R, Abraham OC, 2014. Profile of organ dysfunction and predictors of mortality in severe scrub typhus infection requiring intensive care admission. Indian J Crit Care Med 18: 497-502. 